\title{
The correlation of the prothrombin time and accelerated clopidogrel time in stent thrombosis in patients with drug-eluting stent and bare-metal stent
}

\section{Rreze Koshi*1, Maja Strozzi ${ }^{2}$, Davor Miličić}

'General Hospital ISA GREZDA, Deshmoret e lirise, Gjakova, Kosova

${ }^{2}$ University of Zagreb School of Medicine, University Hospital Centre Zagreb, Zagreb,

Croatia
KEYWORDS: prothrombin time and accelerated prothrombin time, percutaneous coronary intervention, drug-eluting stent, bare-metal stent

CITATION: Cardiol Croat. 2016;11(10-11):467. | DOI: http://dx.doi.org/10.15836/ccar2016.467

*ADDRESS FOR CORRESPONDENCE: Rreze Koshi, General Hospital ISA GREZDA, Deshmoret e lirise, 5000 Gjakova, Kosova. / Phone: +377-44-236-610 / E-mail: rreze.koshi@gmail.com

ORCID: Rreze Koshi, http://orcid.org/ 0000-0002-76532332 - Maja Strozzi, http://orcid.org/0000-0003-4596-8261 Davor Miličić, http://orcid.org/0000-0001-9101-1570

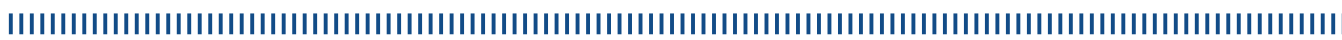

Introduction; The main aim of this study is to determine the correlation of the prothrombin time and accelerated prothrombin time in patients who have stent thrombosis which is implanted drug-eluting stent (DES) and bare-metal stent (BMS). ${ }^{1}$

Patients and Methods: The study is completed and included in 60 patients and we measured the laboratory test parameters of prothrombin time and accelerated prothrombin time. The study was obtained in the prospectively manner in the period from January 2008 to January 2009 in University Hospital Centre Zagreb. The patients were classified in the groups with the cororanography and the Interventional procedure,also we divided the patients with DES and BMS.

Results: With T test we did not find an important significant differences in prothrombin time in the patients with stent thrombosis and without stent thrombosis. ( $\mathrm{T}=1736, \mathrm{P}=0.087$ ). Also we did not find an important significant statistic differences in accelerated prothrombin time in the patients with and without stent thrombosis ( $\mathrm{T}=0.606, \mathrm{P}=0.546$ ).

Conclusion: Prothrombin time and accelerated prothrombin time did not mach any significance in the patients with and without stent thrombosis. Applying the dual of the antiplatelet therapy decrease the incidence of the stent thrombosis. The metaanlaysis of th new inhibitor P2Y12 reduce the mortality after PCI compared with clopidogrel and are very effective in the STEMI patients treated with PCI. Prasurgel and ticagrelor have the same efficacy but more protective of the stent thrombosis is prasurgel is also with the incidence of bleeding.
RECEIVED:

October 3, 2016

ACCEPTED:

October 10, 2016

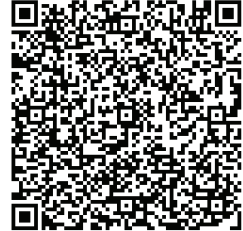

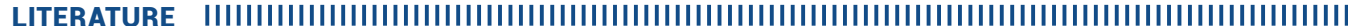

1. Damani SB, Topol EJ. The case for routine genotyping in dual-antiplatelet therapy. J Am Coll Cardiol 2010;56:109-11. DOI: http://dx.doi.org/10.1016/j.jacc.2010.03.029
Cardiologia Croatica $\square$ 2016:11(10-11):467. 